\title{
Local scaling characteristics of Antarctic surface layer turbulence
}

\author{
S. Basu ${ }^{1, *}$, A. Ruiz-Columbié ${ }^{1}$, J. A. Phillipson ${ }^{1, * *}$, and S. Harshan ${ }^{1, * * *}$ \\ ${ }^{1}$ Atmospheric Science Group, Department of Geosciences, Texas Tech University, Lubbock, Texas, USA \\ *now at: Department of Marine, Earth, and Atmospheric Sciences, North Carolina State University, \\ Raleigh, North Carolina, USA \\ ** now at: National Weather Service, St. Louis, Missouri, USA \\ **** now at: Centre for Atmospheric and Oceanic Sciences, Indian Institute of Science, Bengaluru, Karnataka, India
}

Received: 14 March 2010 - Published in The Cryosphere Discuss.: 31 March 2010

Revised: 15 August 2010 - Accepted: 30 August 2010 - Published: 2 September 2010

\begin{abstract}
Over the past years, several studies have validated Nieuwstadt's local scaling hypothesis by utilizing turbulence observations from the mid-latitude, nocturnal stable boundary layers. In this work, we probe into the local scaling characteristics of polar, long-lived stable boundary layers by analyzing turbulence data from the South Pole region of the antarctic plateau.
\end{abstract}

\section{Introduction}

More than two and a half decades ago, Nieuwstadt (1984a,b, 1985 ) introduced the concept of local scaling for stably stratified atmospheric boundary layer (ABL) flows. Based on several second-order moment equations, he hypothesized that the dimensionless combinations of turbulent variables (fluxes, (co-)variances, eddy viscosities etc.), which are measured at the same height could be expressed as "universal" functions of the so-called stability parameter $(\zeta)^{1}$. As a corollary to this hypothesis, he also deduced that in the asymptotic limit of $\zeta \rightarrow \infty$ (known as the z-less stratification regime; Wyngaard, 1973), the dimensionless turbulent quantities should approach constant values. Local scaling could be viewed as a generalization of the well established Monin-

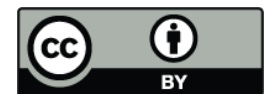

Correspondence to: S. Basu (sukanta_basu@ncsu.edu)

${ }^{1}$ The stability parameter $(\zeta)$ equals to zero for neutrally stratified condition. $\zeta$ greater (less) than zero signifies stable (unstable) regime.
Obukhov (M-O) similarity theory (Monin and Yaglom, 1971; Sorbjan, 1989). The M-O similarity theory is strictly valid in the surface layer (lowest $10 \%$ of the ABL), whereas local scaling describes the turbulent structure of the entire stable boundary layer (SBL; Nieuwstadt, 1984a,b, 1985).

Local scaling has numerous ramifications for several fields in atmospheric science and meteorology. Foremost, it allows us to systematically merge field observations from different field experiments (with variable sensor heights) for extensive statistical analyses, and in turn, to gain valuable insights on SBL (Heinemann, 2004). Therefore, it is not surprising that it has been termed as a "powerful reductionist technique for analysis and prediction" by Brown et al. (1994). In the recent past, in the absence of a formal (universally accepted) theory of SBL, local scaling-based results have quite frequently served as benchmarks for new-generation stably stratified turbulence modeling approaches (for an example see Basu and Porté-Agel, 2006). Local scaling is also an integral part of numerous local closure-based present-day atmospheric models (e.g., Steeneveld et al., 2006; Brown et al., 2008). Lastly, it has established its niche in the applied field of dispersion modeling (Scire et al., 2000).

When the local scaling concept was proposed, observational data from a $200 \mathrm{~m}$ tall tower at Cabauw in the Netherlands provided strong support for this remarkable hypothesis (Nieuwstadt, 1984a,b). Over the years, several studies have provided independent validation for the local scaling hypothesis (e.g., Lenschow et al., 1988; Basu et al., 2006). However, most of these studies have primarily focused on the mid-latitude SBLs. Only a handful have considered SBL turbulence in the polar regions (see Heinemann, 2004, and

Published by Copernicus Publications on behalf of the European Geosciences Union. 
the references therein). The present study intends to shed more light on the local scaling characteristics of polar SBLs by performing rigorous statistical analyses of turbulence data from the South Pole region of the antarctic plateau.

The structure of this paper is as follows. In the following section, we briefly delineate the distinctive features of polar SBLs with respect to mid-latitude nocturnal SBLs. In Sect. 3, we provide the general characteristics of the South Pole region. Our data processing and quality control procedures are described in Sect. 4. Comprehensive results are given in Sect. 5. Section 6 concludes this paper. In order to enhance the readability of this paper, a glossary of symbols is presented in Appendix A.

\section{A brief comparison of polar and mid-latitude SBLs}

In many aspects, SBLs over the polar regions differ significantly from their mid-latitude counterparts (King, 1993). For example, in the mid-latitude, surface inversions over land predominantly form during the nighttime hours. In contrast, due to the mere shortage of insolation (and high surface albedo), the surface inversions over the polar regions are of long-lived (aka persistent) nature. Based on ten years of temperature data at the South Pole, Hudson and Brandt (2005) found that the lapse conditions within a near-surface layer (2-22 m) were observed only $26 \%$ and $8 \%$ of the time during austral summer and winter, respectively. They also reported that throughout these years no signatures of diurnal cycles were found at the South Pole.

Over the mid-latitude, near-neutral residual layers (remnants of the previous day's mixed layer) typically form overlying the nighttime SBLs. Due to the dearth of lapse conditions and diurnal cycles, such layers are rarely present over the polar regions. As a result, quite frequently, the polar SBLs become directly coupled with the free atmosphere. This means that, in comparison to the mid-latitude SBL turbulence, the polar SBL turbulence gets significantly influenced by the gravity wave activities aloft (Zilitinkevich and Calanca, 2000; Zilitinkevich, 2002; Sodemann, 2002).

In spite of these physical differences, the local scaling properties of SBLs over an antarctic ice shelf (King, 1990) and the Greenland ice sheet (Heinemann, 2004) were found to be in good agreement with corresponding mid-latitude values. King (1990) reported that the mean value of normalized vertical variance at $5 \mathrm{~m}$ was approximately $1.42 \pm 0.01$. At $17 \mathrm{~m}$ and $32 \mathrm{~m}$, the corresponding values were $1.57 \pm 0.01$ and $1.55 \pm 0.01$. These numbers were within the range of reported mid-latitude values. Other statistics (e.g., correlation coefficients) documented by King (1990) were also in the vicinity of the corresponding mid-latitude values. Heinemann (2004) drew similar inferences. He found that the local scaling hypothesis was valid even for strong katabatic wind conditions.
In this paper, we further assess the universality of the local scaling concept by analyzing data from the deep interior part of the antarctic continent, which is climatologically quite different from the coastal ice shelves.

\section{Site characteristics}

The South Pole region of the antarctic plateau provides an excellent site for the SBL research. The terrain has a gentle slope of $\sim 0.001 \mathrm{~m} / \mathrm{m}$, which virtually eliminates the influence of strong topographical forcings on the boundary layer evolutions. Furthermore, this region is devoid of several complicated atmospheric processes (e.g., hydraulic jump, barrier winds, flow splitting), which are omnipresent in some other parts of the antarctic continent. The predominant plateau "high" provides cold dry conditions throughout the year (King and Turner, 1997; Turner and Pendlebury, 2004). Some other notable site characteristics are: mostly clear skies, strong surface inversion, infrequent formation of precipitation, light $\left(<5 \mathrm{~ms}^{-1}\right)$ northeast winds, and an average annual temperature of $-49.4{ }^{\circ} \mathrm{C}$ (King and Turner, 1997; Turner and Pendlebury, 2004).

\section{Description of data}

One of the challenging tasks anyone faces when venturing out to do research on antarctic boundary layer turbulence is to find high-resolution datasets. We are fortunate to have access to an extensive public-domain archive of such data collected during the Investigation of Sulfur Chemistry in the Antarctic Troposphere (ISCAT) project. The ISCAT 2000 field campaign took place over the time period of 15 November to 31 December in the year 2000 at the South Pole (Davis et al., 2004). A $22 \mathrm{~m}$ instrumented meteorological tower located near the Atmospheric Research Observatory at the South Pole was used during this field campaign to measure eddy-covariance heat and momentum fluxes, as well as temperature gradients (Davis et al., 2004; Oncley et al., 2004). In this work, we primarily use high-frequency (sampling rate of $20 \mathrm{~Hz}$ ) velocity and temperature ${ }^{2}$ data from two sonic anemometers (ATI K-probes) mounted on the tower at heights of $3.1 \mathrm{~m}$ and $7 \mathrm{~m}$ above the snow surface.

Davis et al. (2004) provided detailed information on the synoptic scale meteorological conditions during ISCAT 2000 and this information will not be repeated here for brevity. From a micrometeorological perspective, it is important to point out that, during the early part of the ISCAT 2000 campaign, the surface layer flow condition was always stably stratified and the wind was coming from the clean-air sector (wind direction of $0-100^{\circ}$ ). After 12 December, both stable

\footnotetext{
${ }^{2}$ Sonic anemometers measure acoustic virtual temperature $\left(t_{\mathrm{c}}\right)$ which is related to air temperature $(T)$ as follows: $t_{\mathrm{c}}=$ $T(1+0.51 q)$. Here $q$ is specific humidity in $\mathrm{g} \mathrm{kg}^{-1}$.
} 

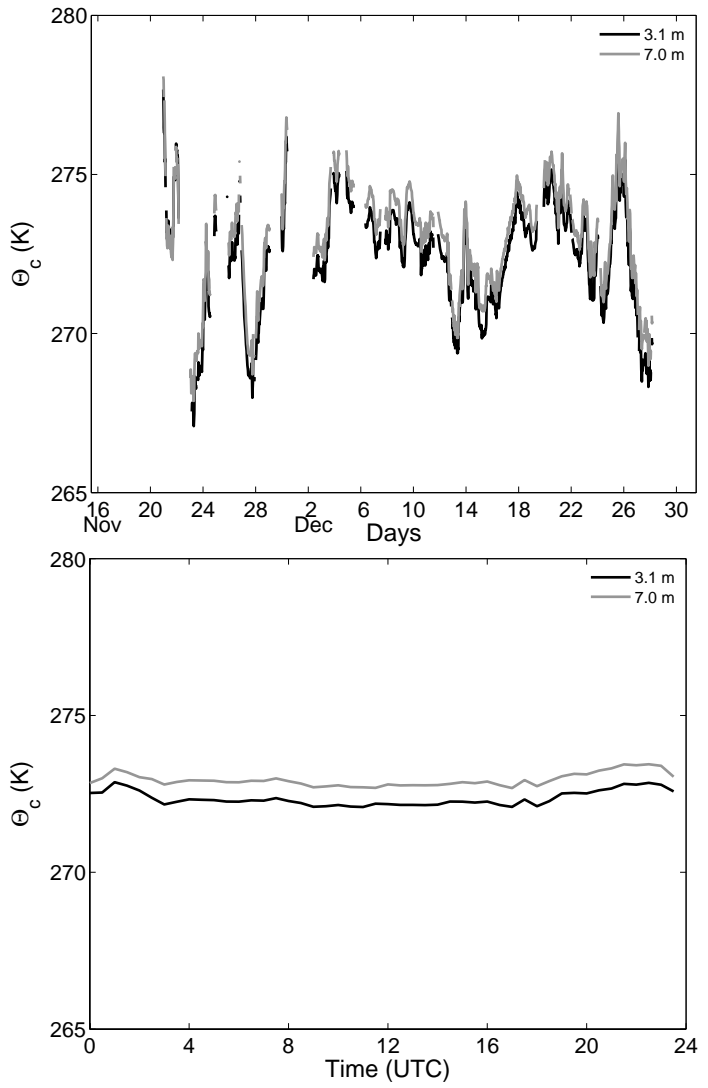

Fig. 1. Time-series (left panel) and diurnal cycle (right panel) of potential (sonic) temperature observed during the ISCAT 2000 field campaign.

and unstable conditions were observed in conjunction with large fluctuations of wind direction (Oncley et al., 2004). However, it is quite evident from Fig. 1 that throughout the duration of the campaign a surface inversion prevailed. No sign of diurnal cycle can be seen. In other words, the ISCAT 2000 archive, even though representative of the austral summer, (likely) contains a substantial amount of long-lived SBL turbulence data.

Rigorous validation of ABL similarity theories (including local scaling) require turbulence measurements which are of pristine quality. Given that the ISCAT 2000 data were collected in the harsh environment of the South Pole, a significant portion of the present work was devoted to stringent quality control and preprocessing of the data. In this regard, we closely followed the suggestions of Vickers and Mahrt (1997), Mahrt (1998), and Basu et al. (2006). Specifically, we follow these steps (see flow chart in Fig. 2):

1. We divided the entire ISCAT 2000 dataset into individual runs of $30 \mathrm{~min}$ durations. At the outset we had a total of 1559 runs from the $3.1 \mathrm{~m}$ sonic anemometer and the same number of runs from the $7 \mathrm{~m}$ sonic anemometer. Each run consisted of four time-series: three compo-

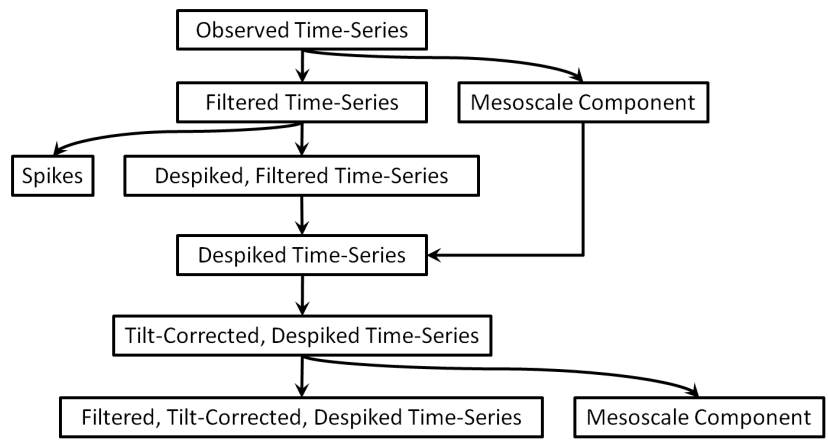

Fig. 2. Flow chart of the quality control and preprocessing steps.

nents of velocity $(u, v$, and $w)$ and sonic temperature $\left(t_{\mathrm{c}}\right)$. We would like to emphasize that all the four timeseries were needed to compute the stability parameter $(\zeta)$. So, if our quality control and preprocessing steps (elaborated below) detected any problem with one timeseries, the entire corresponding run was discarded.

2. We discarded runs if they contained more than $1 \%$ of missing data.

3. Oncley et al. (2004) found spurious spikes in the $7 \mathrm{~m}$ sonic anemometer time-series. These spikes were likely the manifestations of electronic interference. For despiking all the time-series data (including the data from the $3.1 \mathrm{~m}$ sonic anemometer), we utilized the algorithm by Vickers and Mahrt (1997). Since this algorithm involves computing localized standard deviations, it is susceptible to any low-frequency components (e.g., mesoscale motions) present in the time-series. So, we removed any mesoscale component from each timeseries (see Step (5) below for further details) prior to the application of the despiking algorithm. Upon completion of the despiking procedure, the mesoscale component was added back to the time-series. A run was discarded if the total number of spikes detected and removed exceeded $1 \%$ of the total data points in that timeseries.

4. It is well-known in the boundary-layer meteorology literature that small tilts in the sonic anemometer orientation (with respect to true vertical direction) can cause significant biases in the flux estimations. So, in this study, we performed tilt-corrections of the sonic anemometer data using the "planar-fit" method proposed by Wilczak et al. (2001). From every day's collective runs (if there is no missing run, for each sonic anemometer there are 48 runs of $30 \mathrm{~min}$ durations in that day) one set of tilt angles were computed. We also performed yaw rotation following Wilczak et al. (2001) (specifically their Eqs. 45 and 46). 
Table 1. Number of runs discarded by quality control and other criteria.

\begin{tabular}{lcc}
\hline Criterion & $3.1 \mathrm{~m}$ & $7 \mathrm{~m}$ \\
\hline Missing data & 196 & 201 \\
Spike & 12 & 113 \\
Skewness & 17 & 17 \\
Kurtosis & 44 & 56 \\
Nonstationarity & 238 & 260 \\
$\zeta \leq 0 \mathrm{~m}$ & 345 & 329 \\
$\Theta_{c}^{7}-\Theta_{c}^{3.1} \leq 0 \mathrm{~K}$ & 34 & 34 \\
$M<1 \mathrm{~m} \mathrm{~s}^{-1}$ & 63 & 52 \\
$u_{* L}<0.01 \mathrm{~m} \mathrm{~s}^{-1}$ & 3 & 6 \\
$\left|\left\langle w^{\prime} \theta_{c}^{\prime}\right\rangle_{L}\right| \leq 0.001 \mathrm{~K} \mathrm{~m} \mathrm{~s}^{-1}$ & 146 & 122 \\
\hline
\end{tabular}

5. Mesoscale motions do not obey similarity theory and should be removed from the turbulent fluctuations when studying similarity relationships (Vickers and Mahrt, 2003). Following Basu et al. (2006), we partitioned turbulent-mesoscale motions (similar to high-pass filtering) using discrete wavelet transform (Symmlet-8 wavelet) with a gap-scale of $100 \mathrm{~s}$ (see Fig. 1 of Basu et al., 2006, for an illustration).

6. After all these steps, we arrived at a set of runs which were despiked, tilt-corrected, and filtered. Next, these runs were tested to detect possible instrument problems. Following Vickers and Mahrt (1997), the skewness and kurtosis values of each time-series were calculated. If for any time-series, the skewness was outside the range of $(-2,2)$ or the kurtosis was outside the range of $(1,8)$, the corresponding run was discarded.

7. To check for nonstationarities, we subdivided each time-series in six equal intervals and computed the standard deviation of each sub-series $\left(\sigma_{i}, i=1: 6\right)$. If $\max \left(\sigma_{i}\right) / \min \left(\sigma_{i}\right)>2$, the time-series, and in turn, the corresponding run was discarded.

8. The runs were further restricted to satisfy the following constraints:

$-\zeta>0$ (to account for stably stratified conditions only);

- $\Theta_{c}^{7}-\Theta_{c}^{3.1}>0$ (to consider inversion conditions only);

- $M \geq 1 \mathrm{~m} \mathrm{~s}^{-1}$ (to evade very weak wind conditions);

- $u *_{L} \geq 0.01 \mathrm{~m} \mathrm{~s}^{-1}$ and $\left|\left\langle w^{\prime} \theta_{c}^{\prime}\right\rangle_{L}\right| \geq 0.001 \mathrm{~K} \mathrm{~m} \mathrm{~s}^{-1}$ (to avoid uncertain flux measurement conditions);

Here, $\zeta, \Theta_{c}^{7}, \Theta_{c}^{3.1}, M, u_{* L}$ and $\left\langle w^{\prime} \theta_{c}^{\prime}\right\rangle_{L}$ signify stability parameter, mean potential (sonic) temperature ${ }^{3}$ at $7 \mathrm{~m}$,

\footnotetext{
${ }^{3} \mathrm{~A}$ constant surface pressure of $690 \mathrm{hPa}$ was used to calculate potential (sonic) temperature from (sonic) temperature.
}

Table 2. Summary statistics of normalized flux differences.

\begin{tabular}{llll}
\hline $\begin{array}{l}\text { Normalized flux } \\
\text { differences }\end{array}$ & $\begin{array}{l}\text { 50th } \\
\text { percentile }\end{array}$ & $\begin{array}{l}\text { 75th } \\
\text { percentile }\end{array}$ & $\begin{array}{l}\text { 90th } \\
\text { percentile }\end{array}$ \\
\hline$\delta_{u_{*}^{2}}$ & $10.5 \%$ & $17.5 \%$ & $25.3 \%$ \\
$\delta_{\left\langle w^{\prime} \theta_{c}^{\prime}\right\rangle}$ & $13.6 \%$ & $21.9 \%$ & $32.8 \%$ \\
\hline
\end{tabular}

mean potential (sonic) temperature at $3.1 \mathrm{~m}$, mean horizontal wind speed, friction velocity, and sensible heat flux, respectively. Throughout this paper, the subscript " $L$ " on the turbulence quantities are used to specify evaluation using local turbulence quantities. The angular brackets denote averaging over $30 \mathrm{~min}$ period.

9. In Table 1, we summarized the number of runs discarded by the aforementioned quality control steps and constraints. Please note that some of the runs were rejected by more than one criterion. In the end, we were left with 776 and 754 reliable runs for the $3.1 \mathrm{~m}$ and $7 \mathrm{~m}$ sonic anemometers, respectively. Finally, we visually inspected these runs to make sure that other possible errors (e.g., drop outs, discontinuities) were not present. In Sect. 5, we used these runs for testing the local scaling hypothesis.

10. Since the sonic anemometers were located fairly close to the ground, we wanted to make certain that we were indeed going to test the local scaling hypothesis and not the M-O similarity theory. Given that the M-O similarity theory is based on the assumption of negligible (much less than 10\%) vertical flux divergence, we simply needed to demonstrate that significant vertical flux divergences were present in the ISCAT 2000 dataset. So, we calculated the normalized flux differences $(\delta)$ from measurements at $3.1 \mathrm{~m}$ and $7 \mathrm{~m}$, as follows:

$\delta_{u_{*}^{2}}=\left|\frac{\left(u_{*}^{2}\right)_{7.0 \mathrm{~m}}-\left(u_{*}^{2}\right)_{3.1 \mathrm{~m}}}{\left(u_{*}^{2}\right)_{3.1 \mathrm{~m}}}\right| \cdot 100$

$\delta_{\left\langle w^{\prime} \theta_{c}^{\prime}\right\rangle}=\left|\frac{\left\langle w^{\prime} \theta_{c}^{\prime}\right\rangle_{7.0 \mathrm{~m}}-\left\langle w^{\prime} \theta_{c}^{\prime}\right\rangle_{3.1 \mathrm{~m}}}{\left\langle w^{\prime} \theta_{c}^{\prime}\right\rangle_{3.1 \mathrm{~m}}}\right| \cdot 100$

We had a total of 689 runs for which both the $3.1 \mathrm{~m}$ and $7 \mathrm{~m}$ sonic anemometer data were available. In Table 2, we reported the summary statistics of $\delta_{u_{*}^{2}}$ and $\delta_{\left\langle w^{\prime} \theta_{c}^{\prime}\right\rangle}$. Clearly, the $\delta$ values were significantly larger than $10 \%$ for more than $50 \%$ of the runs. Therefore, we concluded that the ISCAT 2000 dataset was appropriate for testing the local scaling hypothesis. 


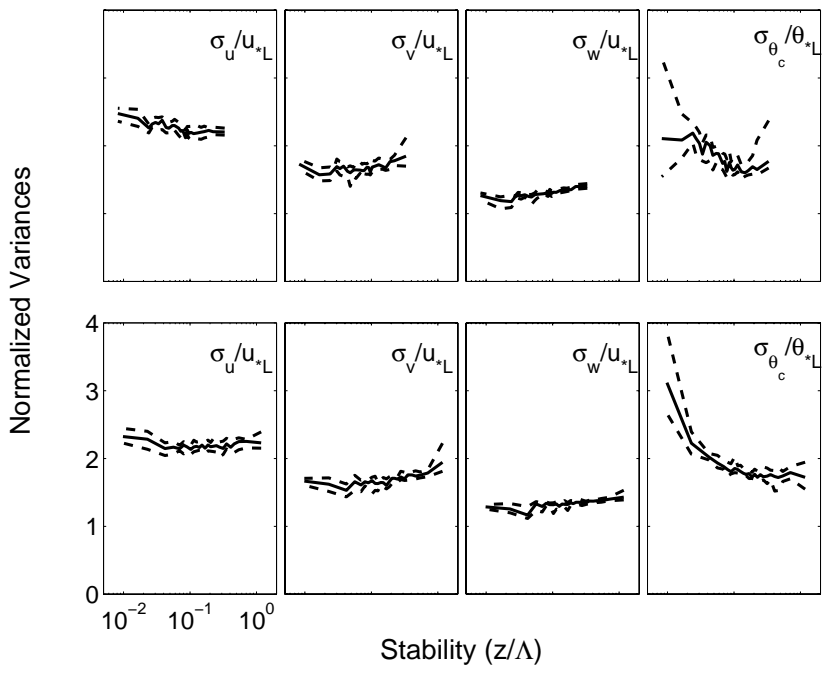

Fig. 3. The panels from left to right represent normalized variances $\sigma_{u} / u_{* L}, \sigma_{v} / u_{* L}, \sigma_{w} / u_{* L}$, and $\sigma_{\theta_{c}} / \theta_{* L}$, respectively. The upper and lower panels correspond to the $3.1 \mathrm{~m}$ and the $7 \mathrm{~m}$ sonic anemometers, respectively. All the panels have identical abscissa and ordinate limits.

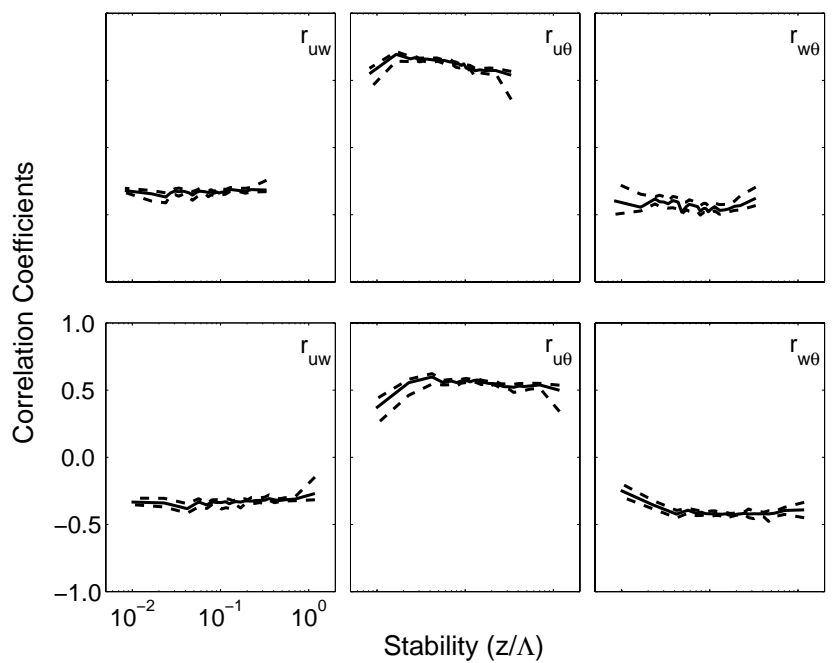

Fig. 4. The panels from left to right represent correlation coefficients $r_{u w}, r_{u \theta}$, and $r_{w \theta}$, respectively; where $r_{u w}=\frac{\left\langle u^{\prime} w^{\prime}\right\rangle}{\sigma_{u} \sigma_{w}}$, $r_{u \theta}=\frac{\left\langle u^{\prime} \theta_{c}^{\prime}\right\rangle}{\sigma_{u} \sigma_{\theta_{c}}}$, and $r_{w \theta}=\frac{\left\langle w^{\prime} \theta_{c}^{\prime}\right\rangle}{\sigma_{w} \sigma_{\theta_{c}}}$. The upper and lower panels correspond to the $3.1 \mathrm{~m}$ and the $7 \mathrm{~m}$ sonic anemometers, respectively. All the panels have identical abscissa and ordinate limits.

\section{Results}

In Figs. 3 to 5, we plotted various normalized turbulence statistics as a function of local stabilities $(\zeta=z / \Lambda)$, where $z$ is the sensor height. $\Lambda$ is the local Obukhov length defined as: $\Lambda=-\frac{\Theta_{c} u_{* L}^{3}}{\kappa g\left\langle w^{\prime} \theta_{c}^{\prime}\right\rangle_{L}}$, where $\kappa$ and $g$ are the von Karman constant, and gravitational acceleration, respectively. We di-

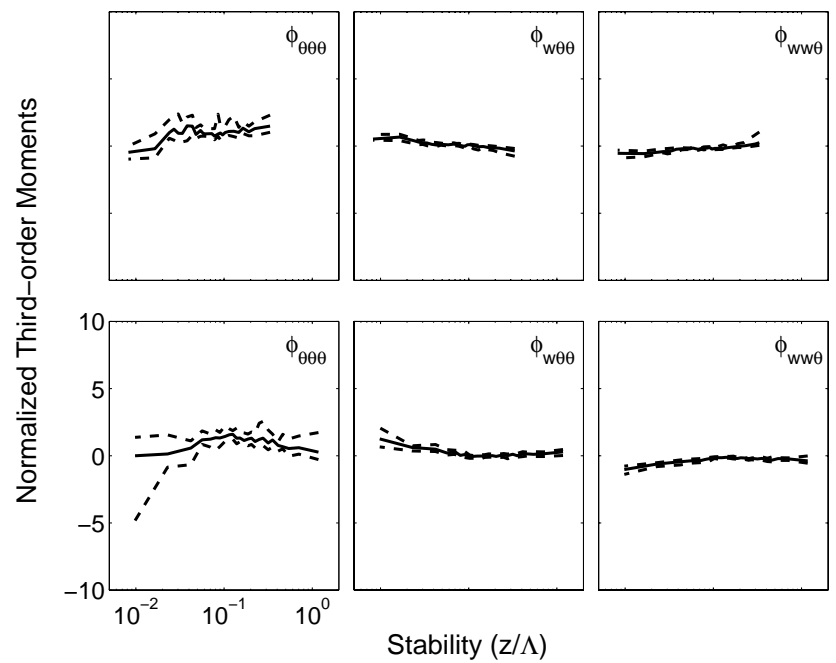

Fig. 5. The panels from left to right represent third-order moments $\phi_{\theta \theta \theta}, \phi_{w \theta \theta}$, and $\phi_{w w \theta}$, respectively; where $\phi_{\theta \theta \theta}=\frac{\left\langle\theta_{c}^{\prime 3}\right\rangle}{\theta_{* L}^{3}}$, $\phi_{w \theta \theta}=\frac{\left\langle w^{\prime} \theta_{c}^{\prime 2}\right\rangle}{u_{* L} \theta_{* L}^{2}}$, and $\phi_{w w \theta}=\frac{\left\langle w^{\prime 2} \theta_{c}^{\prime}\right\rangle}{u_{* L}^{2} \theta_{* L}}$. The upper and lower panels correspond to the $3.1 \mathrm{~m}$ and the $7 \mathrm{~m}$ sonic anemometers, respectively. All the panels have identical abscissa and ordinate limits.

vided the entire range of stabilities into 25 bins of equal samples (e.g., $\sim 30$ data points for sonic anemometer at $7 \mathrm{~m}$ ). For every normalized turbulence statistics (e.g., $\sigma_{u} / u_{* L}$ ), we calculated 25th, 50th, and 75th percentiles from the samples of each bin. The 50th percentile (median) is represented as a solid line in all the figures. On the other hand, the 25th and 75th percentiles are depicted as dashed lines.

In Table 3, we further report the median values of some of the turbulence statistics corresponding to the highest stability bin. Loosely speaking, these median values could be considered as the asymptotic z-less values. For comparison, we also added the results from Basu and Porté-Agel (2006), Nieuwstadt (1984b, 1985), and Heinemann (2004).

Based on Figs. 3 to 5 and Table 3, we summarize:

- All the turbulence statistics from the ISCAT 2000 field campaign portray local scaling and z-less stratification. Most of the statistics actually remain (almost) constant for the entire stability range considered. In contrast to most of the previous studies (e.g., King, 1990), all the figures in this paper show very little scatter. This contrast is primarily due to the removal of the mesoscale motions.

- All the turbulence statistics seem to portray sensor height-independence, with the possible exception of $r_{u \theta}$.

- All the z-less values of turbulence statistics from the present study are in close agreement with the published 
Table 3. The z-less values of turbulence statistics.

\begin{tabular}{cccccccc}
\hline $\begin{array}{c}\text { Turbulence } \\
\text { statistics }\end{array}$ & ISCAT 2000 & \multicolumn{2}{c}{ Basu and Porté-Agel (2006) } & Nieuwstadt & Heinemann \\
& $3.1 \mathrm{~m}$ & $7 \mathrm{~m}$ & $\begin{array}{c}\text { Field } \\
\text { Observations }\end{array}$ & $\begin{array}{c}\text { Wind-tunnel } \\
\text { measurements }\end{array}$ & $\begin{array}{c}\text { Large-eddy } \\
\text { simulations }\end{array}$ & $(1984 \mathrm{~b}, 1985)$ & $(2004)$ \\
\hline$\sigma_{u} / u_{* L}$ & 2.2 & 2.2 & 2.7 & 2.5 & 2.3 & 2.0 & - \\
$\sigma_{v} / u_{* L}$ & 1.9 & 1.9 & 2.1 & - & 1.7 & 1.7 & 1.2 to 1.6 \\
$\sigma_{w} / u_{* L}$ & 1.4 & 1.4 & 1.6 & 1.5 & 1.4 & 1.4 & 4.5 to 7.3 \\
$\sigma_{\theta} / \theta_{* L}$ & 1.8 & 1.7 & 2.4 & 2.7 & 2.4 & 3.0 & -0.15 to -0.30 \\
$r_{u w}$ & -0.32 & -0.27 & -0.21 & -0.28 & -0.32 & - & - \\
$r_{u \theta}$ & 0.54 & 0.50 & 0.51 & 0.55 & 0.56 & - & -0.10 to -0.20 \\
$r_{w \theta}$ & -0.38 & -0.39 & -0.27 & -0.24 & -0.30 & -0.24 & -0.20 \\
\hline
\end{tabular}

results, with the possible exception of $\sigma_{\theta_{c}} / \theta_{* L}$ and $r_{w \theta}$. Please note that $\theta_{* L}$ is defined as: $\theta_{* L}=-\frac{\left\langle w^{\prime} \theta_{c}^{\prime}\right\rangle_{L}}{u_{* L}}$.

- Temperature related statistics (e.g., $\sigma_{\theta} / \theta_{* L}$ ) show some scatters in the near-neutral regime $(\Lambda \rightarrow 0)$. This is to be expected since the temperature fluctuations are very small in the near-neutral regime, and thus the estimated statistics are not very reliable.

- Similar to Dias et al. (1995) and Basu and Porté-Agel (2006), the nondimensionalized third-order moments obey local scaling and essentially remain constant $(\sim 0)$ for the entire stability range considered.

\section{Conclusions}

In this study, we performed rigorous statistical analyses of field observations from the South Pole region of the antarctic plateau to understand the local scaling characteristics of long-lived polar stable boundary layers. We found that the analyzed data strongly support Nieuwstadt's local scaling hypothesis. Based on other published work and the present study, it is reasonable to claim that this remarkable hypothesis is very robust and seems to hold for every known types of stably stratified atmospheric boundary layer flows.

\section{Appendix A}

\section{Glossary of symbols}

$\begin{array}{ll}g & \text { gravitational acceleration } \\ M & \text { mean horizontal wind speed } \\ q & \text { specific humidity } \\ t_{\mathrm{c}} & \text { sonic temperature } \\ r_{\mathrm{mn}} & \begin{array}{l}\text { correlation coefficient between } m \text { and } n \\ u, v, w\end{array} \\ & \begin{array}{l}\text { velocity components in } x, y, \text { and } z \\ \text { directions, respectively }\end{array} \\ u^{\prime}, v^{\prime}, w^{\prime} & \begin{array}{l}\text { velocity fluctuations (around the average) } \\ \text { in } x, y, \text { and } z \text { directions, respectively }\end{array}\end{array}$

$$
\begin{array}{ll}
u_{*} & \text { friction velocity }\left(=\sqrt[4]{\left\langle u^{\prime} w^{\prime}\right\rangle^{2}+\left\langle v^{\prime} w^{\prime}\right\rangle^{2}}\right) \\
\left\langle u^{\prime} w^{\prime}\right\rangle,\left\langle v^{\prime} w^{\prime}\right\rangle & \text { vertical turbulent momentum fluxes } \\
\left\langle u^{\prime} \theta_{c}^{\prime}\right\rangle,\left\langle w^{\prime} \theta_{c}^{\prime}\right\rangle & \text { longitudinal and vertical heat fluxes } \\
z & \text { height above the surface } \\
\kappa & \text { von Karman constant }(=0.40) \\
\Lambda & \text { local Obukhov length }\left(=-\frac{\Theta_{c} u_{* L}^{3}}{\kappa g\left\langle w^{\prime} \theta_{c}^{\prime}\right\rangle_{L}}\right) \\
\sigma_{\mathrm{m}} & \text { standard deviation of } m \\
\theta_{\mathrm{c}}^{\prime} & \text { potential (sonic) temperature fluctuations } \\
& \text { (around the average) } \\
\theta_{*} & \text { temperature scale }\left(=-\frac{\left\langle w^{\prime} \theta_{c}^{\prime}\right\rangle}{u_{*}}\right) \\
\Theta_{\mathrm{c}} & \text { mean potential (sonic) temperature } \\
\zeta & \text { stability parameter }\left(=\frac{z}{\Lambda}\right)
\end{array}
$$

In this paper, the subscript " $L$ " on the turbulence quantities are used to specify evaluation using local turbulence quantities. The angular brackets denote averaging over $30 \mathrm{~min}$ period.

Acknowledgements. This paper is based on work supported by the National Science Foundation under grant ANT-0538453. The authors are grateful to the National Center for Atmospheric Research for making the ISCAT 2000 data public. We greatly acknowledge the valuable comments and suggestions made by the editor and the reviewers.

Edited by: M. Van den Broeke

\section{References}

Basu, S., Porté-Agel, F., Foufoula-Georgiou, E., Vinuesa, J.-F., and Pahlow, M.: Revisiting the local scaling hypothesis in stably stratified atmospheric boundary-layer turbulence: an integration of field and laboratory measurements with large-eddy simulations, Bound.-Lay. Meteorol., 119, 473-500, 2006.

Basu, S. and Porté-Agel, F.: Large-eddy simulation of stably stratified atmospheric boundary layer turbulence: a Scale-Dependent Dynamic Modeling Approach, J. Atmos. Sci., 63, 2074-2091, 2006.

Brown, A. R., Derbyshire, S. H., and Mason, P. J.: Large-eddy simulation of stable atmospheric boundary Layers with a revised 
stochastic subgrid model, Q. J. Roy. Meteor. Soc., 120, 14851512, 1994.

Brown, A. R., Beare, R. J., Edwards, J. M., Lock, A. P., Keogh, S. J., Milton, S. F., and Walters, D. N.: Upgrades to the boundary-layer scheme in the Met Office numerical weather prediction model, Bound.-Lay. Meteorol., 128, 117-132, 2008.

Davis, D. D., Eisele, F., Chen, G., et al.: An overview of ISCAT 2000, Atmos. Environ., 38, 5363-5373, 2004.

Dias, N. L., Brutsaert, W., and Wesely, M. L.: Z-less stratification under stable conditions, Bound.-Lay. Meteorol., 75, 175-187, 1995.

Heinemann, G.: Local similarity properties of the continuously turbulent stable boundary layer over Greenland, Bound.-Lay. Meteorol., 112, 283-305, 2004.

Hudson, S. R. and Brandt, R. E.: A look at the surface-based temperature inversion on the Antarctic Plateau, J. Climate, 18, 16731696, 2005.

King, J. C.: Some measurements of turbulence over an antarctic ice shelf, Q. J. Roy. Meteorol. Soc., 116, 379-400, 1990.

King, J. C.: Contrasts between the Antarctic stable boundary layer and the mid-latitude nocturnal boundary layer, in: Waves and Turbulence in Stably Stratified Flows, edited by: Mobbs, S. D. and King, J. C., Clarendon Press, Oxford, 105-120, 1993.

King, J. C. and Turner, J.: Antarctic Meteorology and Climatology, Cambridge University Press, United Kingdom, 425 pp., 1997.

Lenschow, D. H., Li, X. S., Zhu, C. J., and Stankov, B. B.: The stably stratified boundary layer over the Great Plains. I. Mean and turbulence structure, Bound.-Lay. Meteorol., 42, 95-121, 1988.

Mahrt, L.: Flux sampling errors for aircraft and towers, J. Atmos. Oceanic Tech., 15, 416-429, 1998.

Monin, A. S. and Yaglom, A. M.: Statistical Fluid Mechanics: mechanics of Turbulence, vol. 1, MIT Press, 769 pp., 1971.

Nieuwstadt, F. T. M.: Some aspects of the turbulent stable boundary layer, Bound.-Lay. Meteorol., 30, 31-55, 1984.

Nieuwstadt, F. T. M.: The turbulent structure of the stable, nocturnal boundary layer, J. Atmos. Sci., 41, 2202-2216, 1984.

Nieuwstadt, F. T. M.: A model for the stationary, stable boundary layer, in: Turbulence and Diffusion in Stable Environments, edited by: Hunt, J. C. R., Clarendon Press, 149-179, 1985.
Oncley, S. P., Buhr, M., Lenschow, D. H., Davis, D., and Semmer, S. R.: Observations of summertime NO fluxes and boundarylayer height at the South Pole during ISCAT 2000 using scalar similarity, Atmos. Environ., 38, 5389-5398, 2004.

Scire, J. S., Strimaitis, D. G., and Yamartino, R. J.: A User's Guide for the CALPUFF Dispersion Model (version 5), Earth Tech, Inc., 2000.

Sodemann, H.: Evaluation of a parameterisation for turbulent fluxes of momentum and heat in stably stratified surface layers, Diploma thesis, University of Bayreuth, 2002.

Sorbjan, Z.: Structure of Atmospheric Boundary Layer, PrenticeHall, 317 pp., 1989.

Sorbjan, Z.: Local structure of turbulence in stably stratified boundary layers, J. Atmos. Sci., 63, 1526-1537, 2006.

Steeneveld, G. J., van de Wiel, B. J. H., and Holtslag, A. A. M.: Modeling the evolution of the atmospheric boundary layer coupled to the land surface for three contrasting nights in CASES-99, J. Atmos. Sci., 63, 920-935, 2006.

Turner, J. and Pendlebury, S.: The international Antarctic weather forecasting handbook, $685 \mathrm{pp}$., available at: http://www. antarctica.ac.uk/met/jtu/ftpinst.html, 2004.

Vickers, D. and Mahrt, L.: Quality control and flux sampling problems for tower and aircraft data, J. Atmos. Oceanic Tech., 14, 512-526, 1997.

Vickers, D. and Mahrt, L.: The cospectral gap and turbulent flux calculations, J. Atmos. Oceanic Tech., 20, 660-672, 2003.

Wilczak, J. M., Oncley, S. P., and Stage, S. A.: Sonic anemometer tilt correction algorithms, Bound.-Lay. Meteorol., 99, 127-150, 2001.

Wyngaard, J. C.: On surface layer turbulence, in: Workshop on Micrometeorology, edited by: Haugen, D. A., American Meteorological Society, Boston, 109-149, 1973.

Zilitinkevich, S. S.: Third-order transport due to internal waves and non-local turbulence in the stably stratified surface layer, Q. J. Roy. Meteorol. Soc., 128, 913-925, 2002.

Zilitinkevich, S. S. and Calanca, P.: An extended similarity theory for the stably stratified atmospheric surface layer, Q. J. Roy. Meteorol. Soc., 126, 1913-1923, 2000. 